\title{
Contextual changes influence attention flexibility towards new goals
}

\author{
Malvika Godara $^{1 *}$, Alvaro Sanchez-Lopez ${ }^{2}$, Baptist Liefooghe ${ }^{1}$ and Rudi De Raedt ${ }^{1}$ \\ ${ }^{1}$ Department of Experimental, Clinical \& Health Psychology; Ghent University, Ghent
} (Belgium)

${ }^{2}$ Department of Clinical Psychology; Complutense University of Madrid, Madrid (Spain)

*Corresponding Author:

Malvika Godara

Department of Experimental, Clinical \& Health Psychology

Ghent University

Henri Dunantlaan 2

Ghent 9000

Belgium

malvika.godara@ugent.be

Word Count: 6,881 words (main text)

Keywords: depression, flexibility, context, goal switching, eye-tracking

Data availability statement: The dataset generated during and analyzed during the current study is available on Open Science Framework, osf.io/64qfx 


\begin{abstract}
Introduction: The ability to flexibly process affective information underlies resilient adaptation to changing situations. However, the impact of social contextual changes on affective flexibility has not been examined yet, although this may be crucial to understand how attention operates when changing situations require allocation of different emotional goals.
\end{abstract}

Methods: In a novel eye-tracking task, participants had to deploy the goals to attend to positive or negative facial expressions based on contextual cues.

Results: We found that dysphorics, compared to non-dysphorics, were faster in switching to negative goals, but slower in switching to positive goals, when the context remained constant. However, when the context changed, dysphorics showed an even faster switch to negative goals, while non-dysphorics became more adept at switching towards positive goals.

Discussion: These results suggest that contextual changes exacerbate the negativity and positivity biases exhibited by dysphoric and non-dysphoric individuals, respectively. The study provides evidence for the key role played by contextual changes in guiding attention allocation and thereby emotion regulation processes.

Conclusion: These findings provide preliminary evidence for the role of contextual inflexibility in dysphoria. Results need to be replicated in a clinical sample to further clarify the role of inflexibility over the course of depression. 


\section{Introduction}

An important mechanism underlying efficient implementation of emotion regulation strategies is the ability to flexibly process emotional information (Malooly, Genet \& Siemer, 2013). The flexible cognitive control of stimuli encountered in the environment, termed as cognitive flexibility, is contingent upon the ability to switch between mental sets or goals based upon the demands of the situation (Lezak, 1995). The ability to flexibly shift between changing goals is crucial to develop an adaptive response to life stressors (Fresco, Williams \& Nugent, 2006). Accordingly, greater cognitive flexibility in set-shifting tasks has been linked to higher levels of resilience (Genet \& Siemer, 2011). Set-shifting tasks have been used to assess "affective flexibility", i.e., how people shift attention between affective and nonaffective components of emotional pictures. For example, Genet and colleagues (2013) asked participants to sort emotional pictures based on affective (positive vs. negative) and nonaffective (less than or equal to 1 vs. more than or equal to 2 people in the picture) rules. In this type of paradigm, the inability to inhibit attention to set-irrelevant information and the difficulties in switching to new, set-relevant information are thought to be motivated by deficits in flexible allocation of attention (Genet, Malooly \& Siemer, 2013; Malooly, Genet \& Siemer, 2013). Consequently, problems in flexible allocation of attention to affective information have been found to be associated with low reappraisal ability (Malooly, Genet \& Siemer, 2013), high levels of rumination (De Lissnyder, Koster, Derakashan \& De Raedt, 2010), and lower levels of resilience (Genet \& Siemer, 2011).

These results are in line with conceptual frameworks stating that attention allocation or deployment is one of the key mechanisms employed in emotion regulation (Gross \& Thompson, 2007). Indeed, difficulties in disengaging attention from negative stimuli, have been found to disrupt emotion regulation and maintain or aggravate negative mood (Sanchez, Vazquez, Marker, LeMoult \& Joormann, 2013: Sanchez, Romero \& De Raedt, 2017), and are 
a hallmark of depressive symptomatology (De Raedt \& Koster, 2010). The inability to switch attention away from negative stimuli and attend to positive stimuli when required is reminiscent of a dysfunctional cognitive flexibility mechanism. Thus, it is crucial to investigate the (in)flexibility of attention for affective material, as this can be one crucial feature underlying the onset and maintenance of depressive symptomatology. However, the aforementioned measures of attentional flexibility require individuals to switch between two different types of tasks, attending to affective and non-affective components of emotional material (Genet et al., 2013; Malooly et al., 2013), without taking into consideration the potential impact of contextual factors. In real-life, emotional material seldom occurs without the presence of a larger context, i.e. the situation in which affective information is encountered.

Attention to stimuli, within any given context, is guided by the goals of the individual within that context (Desimone \& Duncan, 1995; Vogt, De Houwer, \& Moors, 2011). Depending on the context, individuals can have higher-order distal goals that function through secondary, proximal goals (Vogt, De Houwer, Moors, Van Damme, \& Crombez, 2010; Moors \& De Houwer, 2006). For example, while walking along a dark street at night, an individual with the distal goal to reach home safely will have the proximal goal of paying attention to threatening individuals on the street. As such, context most likely plays a key role in the deployment of attention to emotional information, and as the context changes, attention allocation should change as well. For example, imagine that that an individual is at a party and that he has the goal "to have a good time". His attention will probably be preferentially directed to the positive affective stimuli at the party. However, upon hearing a loud sound, he will most likely shift attention to negative stimuli in the environment to detect if there is any danger. Therefore, as contexts change, individuals have to switch between different higherorder goals that will likely lead to switching attention between different stimuli in the 
environment. This ability to flexibly switch attention based upon a changing context underlies the core construct of adaptability. Both positive and negative emotions can be considered adaptive to the extent that they are employed in a context-sensitive manner and are appropriate to the current context (Bonanno et al., 2007; Coifman \& Bonanno, 2010). By extension, attention to both positive and negative emotional stimuli could be considered adaptive if it allows for context-appropriate coping behaviors (Mancini, 2015). However, current measures of affective flexibility fail to take into account the influence of contextual changes on attentional flexibility, even though it might be crucial to disentangle these key processes.

Difficulties in switching from a neutral to an emotional task set have been linked to greater persistence on a stressful task (Johnson, 2009a), but have also been found to be associated with higher trait anxiety and increased worry in the long run (Johnson, 2009b). This suggests that switching behavior between affective and non-affective tasks, by itself, might not be the best predictor of long-term resilience, and training switching behavior without context might not promote decreased psychopathology or increased flexibility over time. Corroborating this line of thought, Malooly (2016) found an affective flexibility training to be only as effective as a control training in impacting emotion regulation. This is in line with recent models of emotion regulation which highlight the importance of contextual factors, and suggest that psychopathology may be a product of context-inappropriate inflexible emotion regulation (Aldao, 2013; Bonanno \& Burton, 2013; Bonanno et al., 2004; Kashdan \& Rottenberg, 2010). Flexibility in switching towards non-affective components may not be suitable in contexts wherein attention to affective material might promote better coping and greater resilience (Troy, 2015). For example, if a person receives a poor performance review at work which might jeopardize his/her job, switching away from negative information may in fact adversely impact coping and impede resilience because it 
would inhibit direct action towards resolving performance-related issues. As such, current affective flexibility tasks, measuring flexibility in switching between affective and nonaffective components, are likely not able to effectively index a wide range of crucial attention flexibility processes. Another important caveat to current affective flexibility measurement tasks seems to be the exclusion of inter-emotion attention flexibility, i.e. switching attention between positive and negative information, which can be important in social contexts. In social situations, flexibility in switching attention towards context-appropriate emotions would most likely elicit context relevant responses, and allow contextually-adapted emotion regulation, leading to improved coping and greater resilience. Therefore, it can be assumed that the current paradigms of affective flexibility are not comprehensive enough.

Previous research has shown that inter-emotion attention flexibility is adversely impacted in depression such that, in contexts where it is useful, depressed individuals are still unable to switch their attention away from negative emotional information, i.e. an attention bias for negative information (Rothermund, Voss, \& Wentura, 2008). This inability to switch away from negative information will likely be exacerbated by depressed individuals' lack of context-appropriate reactivity to positive and negative information (Rottenberg, 2005; Rottenberg, Gross \& Gotlib, 2005; Rottenberg \& Hindash, 2015). Therefore, it is of utmost importance to investigate whether switching contexts affects inter-emotion attention flexibility in depressive state. Rottenberg (2007) proposed the emotion context insensitivity theory, which posits that depressive states would be associated with a lack of contextappropriate reactivity to positive and negative emotions, as there are broader reductions in emotional reactivity to changes in the environment. Considerable research has provided support for this theory (Aldao \& Nolen-Hoeksema, 2012; Coifman \& Bonanno, 2009; 2010; Feeser et al., 2013; Rottenberg \& Vaughan, 2008; Troy, Shallcross, \& Mauss, 2013). In line with the emotion context insensitivity theory, Ellis, Beevers \& Wells (2009) found that 
dysphoric individuals demonstrate dysfunctional emotional responding across changing contexts. In response to positive and negative feedback on performance, dysphoric individuals displayed reduced context-appropriate emotional responding, whereas non-dysphoric individuals responded in a context-appropriate manner to both positive and negative feedback. Consequently, one can argue that depressed or dysphoric individuals will have difficulties in switching between positive and negative information because they are unable to engage relevant context-dependent goals. Therefore, in the current study we examined whether switching between different contexts impacts attention switching behavior between positive and negative emotional stimuli in dysphoric individuals.

For the purpose of this study, we developed realistic social scenarios/contexts, each of which had two higher-order, distal goals. These two distal goals functioned through proximal goals of directing attention to positive and negative stimuli. For example, the context "friend's party" consisted of the higher-order, distal goals "to enjoy the party" and "to solve an altercation with friends", which functioned through the proximal goals of "attend to positive" and "attend to negative" respectively. Each of the two proximal goals were coupled to one of two objects (square and circle), which changed meaning based upon the social context. For example, the square object indicated that the "attend to positive" goal needed to be activated in the context of "class presentation", while square object denoted activation of "attend to negative" goal in the "friend's party" context. Participants had to switch between attending to positive or negative emotional stimuli based upon the goals activated by context cues and goal objects. The switching task was developed based on eye-tracking technology. Previous attentional flexibility tasks measure participants' reaction times, wherein participants have to press one of two buttons to indicate a shift of attention (Genet, Malooly \& Siemer, 2013). However, these measures are able to capture only an indirect proxy measure of covert attention (Van Bockstaele et al., 2014). Further, standard reaction time measures often have 
poor psychometrics and are less able to effectively index aberrant attention processes (Zvielli, Vrijsen, Koster \& Bernstein, 2016). In contrast, eye movement tracking, as employed in the current study, allows for a direct and continuous measure of overt attention, and provides a more dynamic and stable index of attentional bias (Waechter et al., 2014). Furthermore, studies using eye tracking, unlike reaction-time tasks, have been able to delineate a stable attention bias in depressed individuals, towards negative emotional information and away from positive stimuli (see Armstrong \& Olatunji, 2012 for a review).

In sum, we developed a novel eye-tracking task to evaluate the ability to switch attention from negative to positive goals and vice versa within social contexts, and to test the role of contextual changes in such attention switching capacities. We obtained the first fixation index, i.e. how quickly participants attend to positive or negative goal-related stimuli, to test the switching capabilities.

In line with previous findings from the affective flexibility literature (Joormann \& Tanovic, 2015), we expected that, when the context remained constant, dysphoric individuals would have more difficulty in switching from a negative to a positive goal (i.e., longer times to fixate on new goal-relevant positive information), but would show swift attention (i.e., shorter times to fixate) towards new negative goal-relevant emotional stimuli when this comprises switching away from a previous positive goal (hypothesis 1). Moreover (hypothesis 2), we did not expect any differences in first fixation times when switching from a negative to a positive goal, and vice versa, for non-dysphoric individuals. As a third hypothesis, regarding conditions of contextual change, in line with general findings of the existence of switch costs (Joormann \& Tanovic, 2015, Monsell, 2003), we hypothesized that changes in context would increase difficulties in repeating attention to and switching between goals for all participants in general (i.e., longer times to fixate on goal-relevant emotional information when context changed than when the context kept the same). Yet, emotion context-insensitivity theory 
posits that individuals in depressogenic states show particularly reduced reactivity to emotional information because of difficulties in processing the ongoing changes in environment (Rottenberg, 2007). Accordingly, as a fourth hypothesis, we expected that the impact of changes in context on attention to goal-relevant emotional information would be particularly pronounced for dysphoric compared to non-dysphoric individuals.

\section{Method}

\section{Participants}

Fifty-three individuals (44 females; $M_{\text {age }}=22.66, S D_{\text {age }}=4.19,18-45$ years) took part in the study ${ }^{1}$. Participants were sampled from the Ghent University research participant pool $(N=134)$, and were invited based on their pre-screening scores on the Anhedonia Depression (AD) subscale of the Mood and Anxiety Symptoms Questionnaire - D30 (MASQ - D30; Wardenaar et al., 2010). However, 2 participants were excluded from data analysis due to low quality of the eye-gaze data $(<50 \%$ of eye-gaze samples recorded). The high dysphoric group were recruited from the top $25 \%$ of scores in the participant pool on the AD subscale of MASQ - D30, >= 25, and the low dysphoric group from the people in the bottom $25 \%$ of the scores in the participant pool, $<=21$. Participants were invited based on their scores on the AD scale of MASQ - D30 conducted at the beginning of the academic year (1 month prior to recruitment), however, they were assigned to the dysphoria group based on their scores on the MASQ - D30 administered at the time of lab session. Accordingly, 24 participants were included in the high dysphoric group $\left(M_{h i g h}=30.77, S D=6.02,25-43\right)$, and 27 participants were part of the low dysphoric group $\left(M_{\text {low }}=18.67, S D=2.69,13-21\right)$, as measured at the time of lab testing. Further, participants were excluded if they had any current, co-morbid psychiatric problems using the Mini-International neuropsychiatric

\footnotetext{
${ }^{1}$ No data was collected related to the ethnicity/culture, measure of income, education, or socioeconomic status of the participants.
} 
interview, which is a short, structured diagnostic interview (Sheehan et al., 1998). The Mini was used to confirm the absence of any psychiatric conditions which the participants had not revealed, and which could otherwise interfere with our study. All participants had normal or corrected-to-normal vision. The study was approved by the ethical committee of the Faculty of Psychology \& Education Sciences at Ghent University. All participants provided informed consent and were compensated for their time $(€ 10)$.

\section{Materials}

Questionnaires. Participants completed the Mood and Anxiety Symptoms Questionnaire - D30 (Wardenaar et al., 2010). The short adaptation of the self-report questionnaire consists of 30 items, out of which 10 items are depression-specific on the AD subscale. Participants had to respond to statements using a 5-point scale, wherein ' 1 ' was "Not at all" and '5' was "Extremely". The items on the AD subscale are reverse scored. MASQ - D30 has a Cronbach's alpha of .92 in young adults, and in our sample the internal consistency was .92 as well.

Apparatus. The stimulus presentation of the experiment was programmed using Eprime Professional 2.0 (2008), and was implemented on a 23-inch high TFT screen, with a resolution of 1920 x 1080 pixels and typical luminance of $300 \mathrm{~cd} / \mathrm{m}^{2}$ (vertical sync frequency $=75 \mathrm{~Hz}$ ). Participants were seated at a distance of $59-65 \mathrm{~cm}$ from the screen. Eye-tracking was accomplished through the use of Tobii TX 300 eye tracker, at a sampling rate of $300 \mathrm{~Hz}$ (binocular). Participants underwent a 9-point calibration procedure. E-prime stimulus presentation and eye-tracking was merged into movie recordings using Tobii studio, which merged stimulus presentation with relevant eye-gaze patterns. Tobii Studio was used to convert the visual eye-gaze data into reaction time attention indices, comprising the time to make a first fixation on goal-relevant stimuli. 


\section{Attention Flexibility Task}

Pictures. Emotional stimuli were obtained from the Karolinska Directed Emotional Faces (KDEF; Goeleven et al., 2009) and Radboud Faces Database (RaFD; Langner et al., 2010). Thirty-seven pictures of the positive category ("happy" emotion) and sixty pictures of the negative category ("angry", "disgust", "sad" and "fearful" emotions) were obtained from KDEF based on high scores for intensity of valence $\left(M_{\text {Negative }}=5.74, S D_{\text {Negative }}=1.70 ; M_{\text {Positve }}\right.$ $\left.=6.10, S D_{\text {Positive }}=1.63\right)$, and arousal $\left(M_{\text {Negative }}=3.61, S D_{\text {Negative }}=1.81 ; M_{\text {Positive }}=3.72\right.$, $S D_{\text {Positive }}=1.91$ ). Twenty-five positive category ("happy" emotion) and forty-three negative category ("fearful”, "disgust” and "angry” emotions) pictures were obtained from RaFD (Caucasian, Adult, Frontal subset), based on high scores for intensity of valence $\left(M_{\text {Negative }}=\right.$ 4.10, $\left.S D_{\text {Negative }}=0.33 ; M_{\text {Positve }}=4.10, S D_{\text {Positive }}=.04\right)$ and valence $\left(M_{\text {Negative }}=2.03, S D_{\text {Negative }}\right.$ $\left.=0.20 ; M_{\text {Positve }}=4.20, S D_{\text {Positive }}=0.30\right)$. Four context images represented an associated context text and did not consist of human figures. Context pictures were obtained from Google Images by filtering the search results according to usage rights, and pictures marked "Labeled for reuse" and "Labeled for noncommercial reuse" were used.

Task. Four textual contexts were developed for the purpose of the study: dinner, party, presentation, and birthday celebration (see Appendix I for contexts presented). The contexts consisted of social situations and described what was taking place in the scene. For example, "You are at the birthday party of your cousin". These contexts were chosen as they are an ecologically valid representation of realistic scenarios individuals may encounter in daily lives. Each context was coupled with a context image which depicted the text in pictorial form, without the presence of any human figures. For example, the party context had a picture of a party scene associated with it.

Every context consisted of two goals, one which prompted the participants to direct attention towards positive stimuli in the contextual "environment", e.g. the goal to enjoy your 
cousin's birthday celebration, and one which required them to look at negative stimuli, e.g. the goal to solve conflict with your family members. Both the goals had an associated goal object, a blue square or blue circle, indicating which goal had to be activated in the particular context. For example, a blue square in a party scene indicated that participants had to activate the goal of looking towards negative stimuli in the context. Even though only two goal objects were used in all contexts (square and circle), the object associated with the goals differed for every scene. For example, in the party scene, square indicated that participants had to look towards negative stimuli, but in the presentation scene, the square denoted the goal to look towards positive stimuli. This was done in order to avoid a single object getting associated with either positive or negative action responses. Further, this allowed us to be certain that participants processed the context to make their decision to look towards positive or negative stimuli (see Appendix I for examples of contexts presented).

The four contexts were then presented in the form of a reaction-time task. Each trial in the task started with a white fixation cross $(8 \mathrm{~mm})$ in the center of a black screen, for $500 \mathrm{~ms}$. Next, a single context image (1024 x 682) appeared on the screen for 3000ms, along with a goal object (square or circle; $100 \times 100$ ) on top of it in the center of the screen. Participants had to fixate their eye-gaze on the center of the screen, i.e. the goal object, for at least $100 \mathrm{~ms}$ before a text appeared at the bottom of the screen asking them to "Press Spacebar for faces". Here, participants could take as much time as they needed to recall the correct response (i.e., look towards positive or towards negative faces) according to the context image and the goal object presented on the screen. Upon pressing the button, a fixation cross appeared for $500 \mathrm{~ms}$, followed by 8 emotional faces ( 4 positive and 4 negative) presented around a fixation cross. Participants had to direct their eye gaze to the correct goal-relevant emotional stimuli (i.e., positive or negative), based on the goal activated, as quickly as possible. The trials ended after the emotional stimuli were presented for $3000 \mathrm{~ms}$. Participants performed 128 trials of the 
main task (see Figure 1 for an example of a trial), and performed equal number of "repeat" (i.e., the goal and/or context was the same as in the previous trial) and "switch" trials (i.e. the goal and/or context was different to the one in the previous trial) for all the different combinations of goals (positive and negative) and contexts. We had 16 trials each for the following combinations: repeat context - repeat goal to negative, repeat context - repeat goal to positive, repeat context - switch goal to negative, repeat context - switch goal to positive, switch context - repeat goal to negative, switch context - repeat goal to positive, switch context - switch goal to negative, and switch context - switch goal to positive. These trials were presented in a pseudo-randomized manner, such that there were 8 blocks (consisting of 16 predefined "repeat" or "switch" trials), which were presented in a random order.

Dependent variable. We obtained one attention index from the eye-tracking data using Tobii Studio: 'First fixation to goal-relevant emotion'. Mean times to make a first fixation (i.e. how quickly participants looked towards the given goal-relevant emotion after the emotional faces had been presented on the screen), were obtained for each of the 128 trials. The 'first fixation to goal-relevant emotion' index allowed us to measure the ability of participants to switch between contexts and between goals. First fixation reaction times (RTs) shorter than $100 \mathrm{~ms}$ were considered to be outliers and removed. Further, any values recorded in Tobii Studio as 0 or blanks were set to missing. For each trial, four RTs were obtained for the goal-relevant faces (either positive or negative depending upon the goal activated). Out of the four RTs, the fastest first fixation was obtained as the final first fixation time for each trial. Finally, the trials were grouped according to the switching condition, and one mean first fixation RT was obtained for each of the conditions. We calculated 8 attention switching variables: Repeat Context - Repeat Goal (Look to positive), Repeat Context - Repeat Goal (Look to negative), Repeat Context - Switch Goal (Look to positive), Repeat Context - Switch Goal (Look to negative), Switch Context - Repeat Goal (Look to positive), Switch Context - 
Repeat Goal (Look to negative), Switch Context - Switch Goal (Look to positive), and Switch Context - Switch Goal (Look to negative). Hypotheses were tested by comparing the ease to engage attention with goal-related stimuli in conditions of switching to new goals and/or contexts and conditions of repeating goals and/or contexts. All analyses in the study were performed using IBM SPSS Statistics software (version 20).

Practice phase and knowledge check. Prior to beginning the main task trials, participants underwent a short practice phase. First, they were acquainted and familiarized with the textual contexts, associated context pictures, and goal objects. Participants then practiced their knowledge of the contexts and goals. They were presented with a single context image along with a goal object (square or circle), and they had to indicate, by pressing one of two buttons, whether they would look towards positive or negative stimuli according to the context-goal combination. All 8 context-goal combinations (4 contexts along with 2 goals objects) were presented 3 times each. Upon the completion of the practice phase, participants underwent a short knowledge check procedure. They were presented with each of 8 contextgoal object combinations, and they had to write down the goal associated with each contextgoal object combination. For example, when presented with the picture of "Friend's party" context along with circle shape, participants had to write down the goal "To enjoy the party". When participants were not able to correctly recall $100 \%$ of the context-goal associations during the knowledge check procedure, they would undergo the practice phase again and repeat the knowledge check procedure afterwards. This knowledge check procedure was performed both pre- and post-task to ascertain whether participants retained the semantic knowledge of goals and the context-goal associations ${ }^{2}$.

\footnotetext{
${ }^{2}$ We analyzed data from the post-task knowledge-check procedure to establish that activation of goals by contextual cues during the main task were adequate. Analyses revealed that the overall recall of contextual cues for all participants was $97.8 \%$, i.e. out of the 408 instances of goal information recall (8 context-goal combinations recalled by 51 participants), there were only 9 instances where a participant did not recall the goal
} 


\section{Procedure}

All participants provided informed consent. First, the participants completed a questionnaires' package ${ }^{3}$ including the MASQ - D30 and then went through the eye-tracker calibration procedure. Next, the participants were introduced to the attention flexibility task, and underwent the practice phase and pre-task knowledge check procedure. They then performed the 128 experimental trials ${ }^{4}$ (16 trials each for the 8 attention switching conditions), and finally, completed the post-task knowledge check. Upon completion of the main task, the MINI psychiatric interview was administered to all the participants to identify the potential occurrence of psychopathology, which may otherwise interfere with the processes being investigated (no subjects were removed based on the results from this interview). This was followed by debriefing about the purpose of the study, and compensation for participation.

\section{Results}

A 2 (Context Switch) x 2 (Goal Switch) x 2 (Goal Type) x 2 (Group) mixed analysis of variance (ANOVA) was conducted with the 'First fixation to Goal-Relevant Emotion' indices. Group (High vs. Low dysphorics) was the between-subjects factor. Context Switch (Repeat vs. Switch Context), Goal Switch (Repeat vs. Switch Goal), and Goal Type (Look to positive vs. Look to negative) were the within-subjects factors. We found significant main effects of Context Switch, $F(1,49)=34.94, p<.001, \eta_{p}{ }^{2}=.42,95 \%$ CI $[.20 ; .57]$, and Goal Switch, $F(1,49)=66.88, p<.001, \eta_{p}^{2}=.58,95 \%$ CI $[.38 ; .69]$. More importantly, these main

information correctly. This confirms that participants largely retained the context-goal associations correctly during the performance of the main task.

${ }^{3}$ As part of the questionnaires package, the participants were administered the following: Mood and Anxiety Symptoms Questionnaire - Dutch (MASQ-D; Wardenaar et al., 2010), Beck Depression Inventory (Van der Does, 2002), and Connor-Davidson Resilience Scale (Connor \& Davidson, 2003). However, only the scores from Anhedonic Depression scale of MASQ-D were used for the purposes of the current study.

${ }^{4}$ Previous eye-tracking studies have used similar number of trials (Caseras et al., 2007; Ellis, Beevers \& Wells, 2011; Leyman et al., 2011; Peña-Esparza, 2011; Schofield et al., 2012) 
effects were qualified by a significant four-way Context Switch x Goal Switch x Goal Type x Group interaction, $F(1,49)=4.59, p<.05, \eta_{p}^{2}=.09,95 \%$ CI $[.00 ; .25]$. (See Appendix II for the full decomposition of the 4-way interaction). Based on our predictions, we now test each individual hypothesis.

Hypothesis 1: high dysphoric individuals have more difficulty in switching to a positive goal as compared to switching to a negative goal when context is repeating

Significant Bonferroni-corrected pairwise comparisons revealed that high dysphorics had faster first fixations when switching from a positive to a negative goal in comparison to switching from a negative to a positive goal $(\mathrm{B}=.15, p<.001, d=1.01,95 \% \mathrm{CI}[.083 ; .228]$; see Figure 2). However, high dysphoric individuals had faster first fixations also when repeating attention to a negative goal in comparison to a positive goal $(\mathrm{B}=.17, p<.001, d=$ $.60,95 \%$ CI $[.082 ; .267])$.

Confirming our hypothesis, we found that high dysphorics found it easier to switch to a negative goal, compared to a positive goal, when the context was constant.

Hypothesis 2: low dysphoric individuals have no difficulty in switching to a positive goal as compared to switching to a negative goal when context is repeating

For low dysphorics, there were no significant differences in switching attention from a negative to a positive goal and switching from a positive to a negative goal $(\mathrm{B}=-.04, p>$ $.250, d=.38,95 \% \mathrm{CI}[-.108 ; .029])$. However, there were also no significant differences in first fixations when repeating attention to negative or positive goals $(\mathrm{B}=.01, p>.850, d=$ $.04,95 \%$ CI [-.079; .095]; see Figure 2).

Confirming our hypothesis, we found that low dysphorics did not differ in switching from a positive to a negative goal and vice versa during context repeat conditions. 
Hypothesis 3: switching and repeating attention to positive and negative goals will be difficult for both high dysphoric and low dysphoric individuals when contexts start switching

Repeating Goals. In line with Hypothesis 3, within-group pairwise comparisons showed that low dysphorics were slower when repeating attention to negative $(\mathrm{B}=-.44, p<$ $.001, d=2.16,95 \% \mathrm{CI}[-.544 ;-.335])$ and positive $(\mathrm{B}=-.11, p=.034, d=.50,95 \% \mathrm{CI}[-.225$; -.009]) goals when the context was switching as opposed to when it was repeating (see Figure 3). The same effects were found for high dysphoric individuals when the context was switching compared to when the context was repeating, i.e. slower first fixations in repeating attention to negative $(\mathrm{B}=-.41, p<.001, d=1.81,95 \% \mathrm{CI}[-.528 ;-.306])$, and positive $(\mathrm{B}=-$ $.19, p=.001, d=.85,95 \% \mathrm{CI}[-.312 ;-.084])$ goals.

In line with our hypothesis, we found that both high and low dysphorics had difficulties in repeating attention to both positive and negative goals when the context changed compared to repeated.

Switching goals. Within-group comparisons revealed that high dysphoric individuals had faster fixations when switching attention to a negative goal $(\mathrm{B}=.11, p=.006, d=.60$, $95 \%$ CI $[.035 ; .191])$ when the context was switching as compared to when the context was repeating. However, there was no significant difference in fixation latencies in switching to positive goals when the context was switching versus repeating $(\mathrm{B}=-.2, p>.600, d=.15$, 95\% CI $[-.091 ; .053])$. This is not in line with our hypothesis, although it is indicative of a negativity bias. Low dysphorics, contrastingly, had faster fixations when switching attention to positive goals $(\mathrm{B}=.19, p<.001, d=1.58,95 \% \mathrm{CI}[.124 ; .260])$ when the context was switching, compared to when the context was repeating. However, there were no significant differences in fixation latencies in switching to negative goals when the context was switching 
versus repeating $(\mathrm{B}=.01, p>.820, d=.11,95 \% \mathrm{CI}[-.066 ; .082])^{5}$, indicating a positivity bias.

Overall, high dysphorics were faster in switching towards negative goals during conditions of context switch compared to when context was repeating. Contrastingly, low dysphorics found it easier to switch towards positive goals when the context switched versus when context repeated.

Hypothesis 4: high dysphoric compared to low dysphoric individuals will have more difficulties in switching attention between goals when contexts start switching

Finally, according to our fourth hypothesis, for conditions where the context switched (i.e., changed from the previous trial), pairwise comparisons showed that high, compared to low dysphorics, found it more difficult to repeat attention towards positive goals $(\mathrm{B}=-.33, p$ $<.001, d=2.64,95 \%$ CI $[-.404 ;-.260])$. On the other hand, the effect was only near significant for repeating attention to negative goals $(\mathrm{B}=-.06, p=.051, d=.57,95 \% \mathrm{CI}[-$ $.122, .0004])$. Further, high dysphorics, compared to low, found it more difficult to switch attention from previous negative towards positive goals $(\mathrm{B}=-.22, p<.001, d=1.49,95 \% \mathrm{CI}$ [-.306; -.137]; see Figure 4). Meanwhile, high dysphorics showed a contrasting pattern, i.e. were faster, in shifting from positive towards negative goals $(\mathrm{B}=.29, p<.001, d=2.12,95 \%$ CI $[.212 ; .368])$, compared to low dysphoric individuals. This indicates an overall difficulty in deploying attention based on context-appropriate positive goals for dysphoric individuals, compared to non-dysphoric individuals, with indications for a negativity bias.

\footnotetext{
5 The Cronbach's alpha for attentional variables of the 8 attention switching conditions was: Repeat Context Repeat Goal (Look to positive) $\alpha=.95$, Repeat Context - Repeat Goal (Look to negative) $\alpha=.94$, Repeat Context - Switch Goal (Look to positive) $\alpha=.94$, Repeat Context - Switch Goal (Look to negative) $\alpha=.95$, Switch Context - Repeat Goal (Look to positive) $\alpha=.97$, Switch Context - Repeat Goal (Look to negative) $\alpha=$ .94, Switch Context - Switch Goal (Look to positive) $\alpha=.96$, and Switch Context - Switch Goal (Look to negative) $\alpha=.97$.
} 
Overall, high, compared to low, dysphorics were faster in switching attention towards negative goals, but slower in repeating and switching attention towards positive goals when the context was switching.

Lastly, we ran Bayesian pairwise comparisons for each of our specific hypotheses to provide more confidence to our frequentist analysis. The findings from the Bayesian analyses largely supported the findings from the frequentist analysis described in the paragraphs above (see Appendix II for more details). However, two findings differed. First, for the comparison between switching to positive versus negative goals in low dysphorics, we found anecdotal evidence in favor of the null when the context is constant (hypothesis 2). This indicates that it cannot be claimed with certainty that there were no significant differences for low dysphorics in switching attention to positive or negative goals when the context was constant. Second, for the comparison between context repeat versus context switch when repeating attention to positive goals, we found anecdotal evidence for low dysphorics (hypothesis 3). This suggests that we cannot claim with certainty that low dysphorics were significantly slower in repeating attention to positive goals when the context switched versus repeated. However, the Bayes factors for the majority of the other comparisons yielded strong to decisive evidence in line with our hypotheses.

\section{Discussion}

The aim of the current study was to examine the impact of contextual changes on flexibility in attending to emotional information in dysphoric and non-dysphoric individuals.

First, we found that dysphorics have greater ease in directing attention towards a negative goal when the context is not changing, whereas non-dysphorics find it equally easy to repeat attention to both negative and positive goals (hypotheses 1 and 2). Further, when the context is not changing, we found that it is easier for dysphoric people to switch to a negative 
goal, but it is more difficult for them to switch to a positive goal. For example, when at a party, a dysphoric individual would find it easier to switch their attention from people enjoying the party to the one upset-looking person in the corner, but they would be slower to make the reverse switch. In line with previous research (Peckham, McHugh \& Otto, 2010), these findings suggest that dysphoric or depressed individuals struggle with shifting their attention away from negative information (for a review see De Raedt \& Koster, 2010).

Second, regarding conditions of contextual change, we expected that contextual changes would create difficulties for all individuals, but would especially inflate the time it takes for dysphoric individuals to direct their attention to goal-relevant emotional information when repeating and switching between goals (hypotheses 3 and 4). Accordingly, we found that although everyone experienced difficulties in repeating and switching attention towards valence-specific goals due to contextual changes, dysphoric, compared to non-dysphoric, individuals experienced significantly more difficulties in repeating and switching attention towards positive goals, when the contexts changed. Contrary to our fourth hypothesis, we found that both dysphoric and non-dysphoric individuals seemed to show greater ease in switching (i.e., faster times to fixate) towards valence-specific goal-relevant information when the contexts were switching.

Although we found that both dysphoric and non-dysphoric individuals experience greater difficulty in repeating attention to both negative and positive goals when the context is switching, these difficulties are significantly more pronounced in dysphoric individuals when repeating and switching attention towards positive goals. This finding implies that as the environment begins to change, all individuals need some time to adapt to it, but dysphoric individuals seem to particularly struggle with this change in their environment when it comes to directing attention to goal-relevant positive stimuli. Further, it seems that dysphoric individuals find it specifically easier to switch to a negative goal when the context is 
switching, whereas non-dysphorics seem to find it more difficult to make this switch. For example, dysphorics would find it easier to switch their attention from happy people at a party to angry people on a street when they leave the party, whereas low dysphorics would struggle to make this type of switch. These findings seem to be in line with the emotion-context insensitivity theory proposed by Rottenberg (2007; Rottenberg, Gross \& Gotlib, 2005), which posits that depressogenic individuals would likely display more mood-dependent changes in emotional reactivity. Further, these findings converge with empirical results which show that dysphoric individuals display mood-dependent changes in emotional reactivity to emotional information due to broader reductions in processing of contextual information (Ellis, Beevers, \& Wells, 2009). Inversely, we also found that non-dysphorics find it easier to switch from a negative to a positive goal when context is switching, whereas dysphorics are slower in making that attention switch. Practically, this would imply, for instance, that dysphorics take longer to switch their attention from an angry boss at a job performance review to colleagues who look happy at an office party, whereas non-dysphorics are quicker to make this switch. This finding from non-dysphoric individuals is parallel to the finding of Ellis and colleagues (2009), wherein non-dysphoric individuals showed more intense positive reactivity when the context changed from a negative to a positive feedback.

Taken together, we show that dysphoric individuals find it easier to maintain and switch attention towards negative goals, and non-dysphoric individuals display a similar propensity towards positive goals. These findings replicate previous research (Joormann \& Tanovic, 2015). A novel finding of our study is that for all individuals it is much more difficult to maintain attention to both positive and negative goals when situations within which these goals are activated are dynamically changing, although these difficulties are significantly more pronounced for dysphoric individuals in case of positive goals. This finding of intra-emotion context-dependent inflexibility is in line with the recent view which 
posits that contextual changes would lead to greater difficulties in emotional flexibility and employment of context-appropriate emotion regulation strategies (Aldao, 2013), but until now, this had not yet been directly tested. Another important result from the current study is that dysphorics find it easier to switch towards negative goals when changing contexts, and non-dysphorics display a similar pattern for positive goals. Both dysphoric and non-dysphoric individuals seem to be quicker in directing their attention towards negative and positive goals, respectively, when the situation is the most complex, i.e. both the goals and contexts are changing. This finding would suggest the presence of a homeostatic mechanism of returning attention to a mood- or schema-congruent 'basic emotional goal'. This corresponds with the extant literature on schema-congruent biases, i.e. a negativity bias in depressed individuals and a positivity bias in non-depressed or healthy individuals (Cummins \& Nistico, 2002; Gotlib et al., 2004). As depressed individuals tend to have a bias towards negativity, one can extrapolate from our findings that this bias would exaggerate and become more rigid when the contexts within which emotional information occurs are unpredictable and changing, mirroring real-life scenarios. In a similar vein, for healthy, non-depressed individuals these changeable contextual situations would enhance their bias towards positive emotional information, making them quicker in approaching positive goals.

Our findings have novel implications, both for research and clinical application. First, our findings clarify the (in)flexibility patterns in dysphoric individuals, as a function of their ability to switch attention between contexts and emotional goals (Stange, Alloy, \& Fresco, 2017). In line with this idea, we found that dysphoric individuals have a greater inflexibility, and that changing contexts seems to exacerbate their negativity bias. Further, we can deduce that this contextual inflexibility precipitates the use of context-inappropriate emotionregulation strategies, such as attention allocation. Given that contextual changes, i.e. shifting real-life situations, are universal, this contextual inflexibility is likely to lead to a failure to 
attend to and achieve goals, which in turn will lead to greater frustration and hopelessness. Second, our use of a high-risk behavioral design and the exposure of individuals to several contexts allowed us to infer that reduced contextual attention flexibility, and largely behavioral inflexibility, may be an important mechanism in depression (Stange et al., 2017).

The present study is the first to connect contextual attentional behavioral (in)flexibility to the presence of depressogenic symptoms. This is important as this novel approach can allow us to study whether improvements or changes in flexibility lead to lowered depressive symptoms and long-term prevalence of depression. In addition, the findings from this study can inform current attention training procedures, expanding the focus towards (in)flexibility in attention from the considerable work on attention bias. Current attention trainings for depressed individuals are aimed towards reducing the attention bias for negative information without taking into account the contextual influences on it. This may be the reason why these trainings have not been effective and tend to do little to alleviate this bias (Cristea, Kok, \& Cuijpers, 2015; Mogoaşe, David, \& Koster, 2014). Our results are indicative that a contextual attention inflexibility mechanism in depression functions in conjunction with negative attention bias mechanisms. This would imply that both flexibility and negative bias mechanisms in depressed individuals need to be trained concurrently to produce a substantial change in depressogenic symptoms.

Despite the novelty and strengths of this study, there are several limitations which need to be addressed in future studies. First, the current study supports the view that (in)flexibility prompts depression. However, our employment of a dysphoric sample precludes any conclusive assertions. Studies need to be conducted in individuals with Major Depressive Disorder (MDD) to fully validate the claim presented by the results of the current study. Further, studies are required in which individuals at-risk of developing depression are tested for their (in)flexibility patterns, such as children of individuals suffering from MDD, to 
effectively ascertain the inflexibility-depression relationship as a possible vulnerability factor. Additionally, to tease out the differences in flexibility patterns across the range of the depressive disorder, both individuals who suffer the first episode of onset of depression and individuals who are currently remitted, need to be prospectively examined. This would allow us to infer whether attentional inflexibility is a by-product of MDD or a vulnerability factor which increases with the number of episodes, as has been suggested for attentional bias by De Raedt \& Koster (2010). Second, our study employed a cross-sectional, experimental design which precludes any conclusions or claims pertaining to the lifetime concurrence of inflexibility and depressed mood. Multi-wave longitudinal studies, employing ecological momentary assessment, would be useful in shedding light on the extent to which flexibility and depressogenic symptoms occur proactively and concurrently. This would inform our view as to how (in)flexibility contributes to depression, and vice versa. An important limitation of the present study concerns the impact of the contexts themselves. In our study, we employed 4 social contexts with 2 goals each which were derived from real-life situations. However, it is possible that different individuals might perceive these contexts differently. For example, an individual might find the prospect of going to a friend's party to be a positive event, another individual who prefers more intimate social settings might perceive the party as a more negative event. As such, the appraisal of the contexts themselves might play a role. Although in the present study our primary concern was to investigate the impact of contextual changes rather than the impact of context appraisal itself, future studies might benefit from collecting valence and arousal ratings pertaining to contexts as well. Further, another related limitation concerning the nature of contexts involves the question of disentangling the effects of the contexts and the goals. In our study, the goals are enmeshed with the contexts themselves. As such, several differential effects are embedded together, i.e. the impact of the nature of context, and the impact of the nature of the goal itself on switching behavior. Although our 
new design has demonstrated reliability and validity to detect individual differences in goalswitching attention within and across context disposals, future research could benefit from disentangling context- and goal-specific processes. Further, based on the theoretical model of inflexibility proposed by Stange \& colleagues (2017), the current study tested only a single variable, the affective shifting flexibility. A recent study of Everaert \& colleagues (2018), found that depressed individuals tended to generate both more biased and inflexible interpretations of ambiguous social environments. This finding supports the idea that inflexibility is a vulnerability factor for depression and impacts emotion-regulation strategies across-the-board. Therefore, future studies need to be conducted wherein the different variables of the inflexibility model, such as coping and explanatory flexibility, are experimentally manipulated along with affective shifting flexibility. This would allow us to obtain larger picture, and thus a wider understanding, of how the different components of inflexibility mechanism influence each other and MDD. Lastly, an important future direction will be to replicate the study in the current form. Two findings from our frequentist analyses deviated from the results of the Bayesian analysis. These discrepancies could be a due to lack of statistical power in detecting differences. Therefore, it is important to replicate the current study so as to clarify the pattern and direction of effects in non-dysphoric individuals. Finally, a key limitation of the study relates to demographic data collection. In the current study, we did not collect data related to the ethnicity/culture, measure of income, education, or socioeconomic status of the participants. This precludes any conclusions related to the applicability of the results to a wider, more culturally/ethnically and socio-economically diverse subsets of population. As such, future studies are needed to replicate the validity of these results in more diverse samples.

In conclusion, the current study advances our knowledge of how contextual attention flexibility disrupts the context-appropriate use of attention allocation strategies, which in turn 
informs depressogenic symptoms. We found that shifting between contexts made it difficult for dysphoric individuals to maintain their attention allocation strategies, i.e. maintain their goals. Meanwhile, complex shifting between contexts and goals, enforced rigid, valencespecific strategies which ultimately disposed over greater inflexibility. These findings provide preliminary evidence for the existence of an essential role of context-based attention flexibility in explaining depression, and could spur further future research into examining this possible, crucial determinant of depression. 


\section{Compliance with Ethical Standards}

Funding: This research was supported by Grant BOF16/GOA/017 for a Concerted Research Action of Ghent University awarded to Rudi De Raedt. Alvaro Sanchez-Lopez is supported by the Program for the Attraction of Scientific Talent of the Community of Madrid. Baptist Liefooghe is supported by Methusalem Grant BOF16/MET_V/002 of Ghent University.

Conflict of interest: All the authors declare that they have no conflicts of interest.

Ethical approval: All procedures performed in studies involving human participants were in accordance with the ethical standards of the ethical committee of the Faculty of Psychology \& Education Sciences at Ghent University (EC reference: 2017/12a) and with the 1964 Helsinki declaration and its later amendments or comparable ethical standards.

Informed consent: Informed consent was obtained from all individual participants included in the study. 


\section{$\underline{\text { References }}$}

Aldao, A. (2013) The future of emotion regulation research: Capturing context. Perspectives on Psychological Science, 8, 155-72. doi: 10.1177/1745691612459518

Aldao, A., \& Nolen-Hoeksema, S. (2012). The influence of context on the implementation of adaptive emotion regulation strategies. Behaviour Research and Therapy, 50, 493-501. doi: 10.1016/j.brat.2012.04.004

Armstrong, T., \& Olatunji, B. O. (2012). Eye tracking of attention in the affective disorders: A meta-analytic review and synthesis. Clinical Psychology Review, 32, 704-723. doi: 10.1016/j.cpr.2012.09.004

Bonanno, G. A., \& Burton, C. L. (2013). Regulatory flexibility: An individual differences perspective on coping and emotion regulation. Perspectives on Psychological Science, 8, 591612. doi: 10.1177/1745691613504116.

Bonanno, G. A., Colak, D. M., Keltner, D., Shiota, M. N., Papa, A., Noll, J. G., Putnam, F. W. \& Trickett, P. K. (2007) Context matters: The benefits and costs of expressing positive emotion among survivors of childhood sexual abuse. Emotion, 7, 824-37. doi: 10.1037/15283542.7.4.824

Bonanno, G. A., Papa, A., Lalande, K., Westphal, M. \& Coifman, K. (2004) The importance of being flexible: The ability to both enhance and suppress emotional expression predicts long-term adjustment. Psychological Science, 15, 482-87. doi: 10.1111/j.09567976.2004.00705.x.

Caseras, X., Garner, M., Bradley, B. P., \& Mogg, K. (2007). Biases in visual orienting to negative and positive scenes in dysphoria: An eye movement study. Journal of Abnormal Psychology, 116, 491. doi: 10.1037/0021-843X.116.3.491 
Coifman, K. G., \& Bonanno, G. A. (2009). Emotion context sensitivity in adaptation and recovery. In A. M. Kring, \& D. M. Sloan (Eds.) Emotion regulation and psychopathology: A transdiagnostic approach to etiology \& treatment (pp. 157-173). New York: Guilford.

Coifman, K. G. \& Bonanno, G. A. (2010) When distress does not become depression: Emotion context sensitivity and adjustment to bereavement. Journal of Abnormal Psychology 119, 479-90. doi: 10.1037/a0020113

Connor, K. M., \& Davidson, J. R. (2003). Development of a new resilience scale: The Connor-Davidson resilience scale (CD-RISC). Depression and Anxiety, 18, 76-82. doi: 10.1002/da.10113

Cristea, I. A., Kok, R. N., \& Cuijpers, P. (2015). Efficacy of cognitive bias modification interventions in anxiety and depression: meta-analysis. The British Journal of Psychiatry, 206, 7-16. doi: 10.1192/bjp.bp.114.146761

Cummins, R. A., \& Nistico, H. (2002). Maintaining life satisfaction: The role of positive cognitive bias. Journal of Happiness Studies, 3, 37-69. doi: 10.1023/A:1015678915305

De Lissnyder, E., Koster, E. H., Derakshan, N., \& De Raedt, R. (2010). The association between depressive symptoms and executive control impairments in response to emotional and non-emotional information. Cognition and Emotion, 24, 264-280. doi: $10.1080 / 02699930903378354$

De Raedt, R., \& Koster, E. H. (2010). Understanding vulnerability for depression from a cognitive neuroscience perspective: A reappraisal of attentional factors and a new conceptual framework. Cognitive, Affective, \& Behavioral Neuroscience, 10, 50-70. doi:

10.3758/CABN.10.1.50 
Desimone, R., \& Duncan, J. (1995). Neural mechanisms of selective visual attention. Annual Review of Neuroscience, 18, 193-222. doi:10.1146/annurev.ne.18.030195.001205

Deveney, C. M., \& Deldin, P. J. (2006). A preliminary investigation of cognitive flexibility for emotional information in major depressive disorder and non-psychiatric controls. Emotion, 6, 429-437. doi: 10.1037/1528-3542.6.3.429

Ellis, A. J., Beevers, C. G., \& Wells, T. T. (2009). Emotional dysregulation in dysphoria: Support for emotion context insensitivity in response to performance-based feedback. Journal of Behavior Therapy and Experimental Psychiatry, 40, 443-454. doi:

10.1016/j.jbtep.2009.05.002

Ellis, A. J., Beevers, C. G., \& Wells, T. T. (2011). Attention allocation and incidental recognition of emotional information in dysphoria. Cognitive Therapy and Research, 35, 425433. doi: 10.1007/s10608-010-9305-3

Everaert, J., Bronstein, M. V., Cannon, T. D., \& Joormann, J. (2018). Looking through tinted glasses: Depression and social anxiety are related to both interpretation biases and inflexible negative interpretations. Clinical Psychological Science, 6, 1-12. doi: $10.1177 / 2167702617747968$

Feeser, M., Schlagenhauf, F., Sterzer, P., Park, S., Stoy, M., Gutwinski, S., ... \& Ströhle, A. (2013). Context insensitivity during positive and negative emotional expectancy in depression assessed with functional magnetic resonance imaging. Psychiatry Research: Neuroimaging, 212, 28-35. doi: 10.1016/j.pscychresns.2012.11.010

Fresco, D. M., Williams, N. L., \& Nugent, N. R. (2006). Flexibility and negative affect: Examining the associations of explanatory flexibility and coping flexibility to each other and to depression and anxiety. Cognitive Therapy and Research, 30, 201-210. doi: $10.1007 / \mathrm{s} 10608-006-9019-8$ 
Genet, J. J., Malooly, A. M., \& Siemer, M. (2013). Flexibility is not always adaptive: Affective flexibility and inflexibility predict rumination use in everyday life. Cognition and Emotion, 27, 685-695. doi: 10.1080/02699931.2012.733351

Genet, J. J., \& Siemer, M. (2011). Flexible control in processing affective and nonaffective material predicts individual differences in trait resilience. Cognition and Emotion, 25, 380-388. doi: 10.1080/02699931.2010.491647

Goeleven, E., De Raedt, D., Leyman, L., \& Verschuere, B. (2008). The Karolinska Directed Emotional Faces: A validation study, Cognition and Emotion, 22, 1094-1118. doi: $10.1080 / 02699930701626582$

Gotlib, I. H., Krasnoperova, E., Yue, D. N., \& Joormann, J. (2004). Attentional biases for negative interpersonal stimuli in clinical depression. Journal of Abnormal Psychology, 113, 127-135. Doi: 10.1037/0021-843X.113.1.127

Gross, J. J., \& Thompson, R. A. (2007). Emotion Regulation: Conceptual Foundations. In J. J. Gross (Ed.), Handbook of emotion regulation (pp. 3-24). New York, NY, US: Guilford Press.

Haines, S. J., Gleeson, J., Kuppens, P., Hollenstein, T., Ciarrochi, J., Labuschagne, I., ... \& Koval, P. (2016). The wisdom to know the difference: Strategy-situation fit in emotion regulation in daily life is associated with well-being. Psychological Science, 27, 1651-1659. doi: $10.1177 / 0956797616669086$

Johnson, D. R. (2009a). Attentional control capacity for emotion: An individual-difference measure of internal controlled attention. Cognition and Emotion, 23, 1516 -1536. doi: $10.1080 / 02699930802437095$ 
Johnson, D. R. (2009b). Emotional attention set-shifting and its relationship to anxiety and emotion regulation. Emotion, 9, 681. doi: 10.1037/a0017095

Joormann, J., \& Tanovic, E. (2015). Cognitive vulnerability to depression: examining cognitive control and emotion regulation. Current Opinion in Psychology, 4, 86-92. doi: 10.1016/j.copsyc.2014.12.006

Kalisch, R., Müller, M. B., \& Tüscher, O. (2015). A conceptual framework for the neurobiological study of resilience. Behavioral and Brain Sciences, 38. doi: 10.1017/S0140525X1400082X

Kashdan, T. B., \& Rottenberg, J. (2010). Psychological flexibility as a fundamental aspect of health. Clinical Psychology Review, 30, 865-878. doi: 10.1016/j.cpr.2010.03.001

Langner, O., Dotsch, R., Bijlstra, G., Wigboldus, D. H., Hawk, S. T., \& Van Knippenberg, A. D. (2010). Presentation and validation of the Radboud Faces Database. Cognition and Emotion, 24, 1377-1388. doi: 10.1080/02699930903485076

Leyman, L., De Raedt, R., Vaeyens, R., \& Philippaerts, R. M. (2011). Attention for emotional facial expressions in dysphoria: An eye-movement registration study. Cognition and Emotion, 25, 111-120. doi: 10.1080/02699931003593827

Lezak, M. D. (1995). Neuropsychological assessment (3rd ed.). New York: Oxford University Press.

Luthar, S. S., Cicchetti, D., \& Becker, B. (2000). The construct of resilience: A critical evaluation and guidelines for future work. Child Development, 71, 543-562. doi: $10.1111 / 1467-8624.00164$ 
Malooly, A. M. (2016). Training Affective Flexibility: Effects of an Affective-Control Training Task on Emotion Regulation. (Unpublished Doctoral Dissertation). University of Miami, Coral Gables, FL. Retrieved from: Open Access Dissertations. 1758.

Malooly, A. M., Genet, J. J., \& Siemer, M. (2013). Individual differences in reappraisal effectiveness: The role of affective flexibility. Emotion, 13, 302. doi: 10.1037/a0029980

Mancini, A. D. (2015). Are positive appraisals always adaptive?. Behavioral and Brain Sciences, 38. doi:10.1017/S0140525X14001630, e113

Mogoaşe, C., David, D., \& Koster, E. H. (2014). Clinical efficacy of attentional bias modification procedures: An updated meta-analysis. Journal of Clinical Psychology, 70, 1133-1157. doi: 10.1002/jclp.22081

Moors, A., \& De Houwer, J. (2006). Automaticity: a theoretical and conceptual analysis. Psychological Bulletin, 132, 297. Doi: 10.1037/0033-2909.132.2.297

Monsell, S. (2003). Task switching. Trends in Cognitive Sciences, 7, 134-140. doi: $10.1016 / \mathrm{S} 1364-6613(03) 00028-7$

Murphy, F. C., Michael, A., \& Sahakian, B. J. (2012). Emotion modulates cognitive flexibility in patients with major depression. Psychological Medicine, 42, 1373-1382. doi: $10.1017 / \mathrm{S} 0033291711002418$

Peckham, A. D., McHugh, R. K., \& Otto, M. W. (2010). A meta-analysis of the magnitude of biased attention in depression. Depression and Anxiety, 27, 1135-1142. doi: 10.1002/da.20755

Peña-Esparza, Y. (2011). Attentional biases in dysphoric college students.

Psychology Software Tools, Inc. [E-Prime 2.0.8.22]. (2008). Retrieved from http://www.pstnet.com 
Rothermund, K., Voss, A., \& Wentura, D. (2008). Counter-regulation in affective attentional biases: a basic mechanism that warrants flexibility in emotion and motivation. Emotion, 8, 34. doi: 10.1037/1528-3542.8.1.34

Rottenberg, J. (2007). Major Depressive Disorder: Emerging Evidence for Emotion Context Insensitivity. In J. Rottenberg \& S. L. Johnson (Eds.), Emotion and psychopathology: Bridging affective and clinical science (pp. 151-165). Washington, DC, US: American Psychological Association. doi: 10.1037/11562-007

Rottenberg, J., Gross, J. J., \& Gotlib, I. H. (2005). Emotion context insensitivity in major depressive disorder. Journal of Abnormal Psychology, 114, 627-639. doi: 10.1037/0021843X.114.4.627

Rottenberg, J., \& Hindash, A. C. (2015). Emerging evidence for emotion context insensitivity in depression. Current Opinion in Psychology, 4, 1-5. doi: 10.1016/j.copsyc.2014.12.025

Rottenberg, J., \& Vaughan, C. (2008). Emotion expression in depression: Emerging evidence for emotion context-insensitivity. In Emotion regulation (pp. 125-139). Springer, Boston, MA.

Sanchez, A., Romero, N., \& De Raedt, R. (2017). Depression-related difficulties disengaging from negative faces are associated with sustained attention to negative feedback during social evaluation and predict stress recovery. PloS one, 12, e0175040. doi: 10.1371/journal.pone.0175040

Sanchez, A., Vazquez, C., Marker, C., LeMoult, J., \& Joormann, J. (2013). Attentional disengagement predicts stress recovery in depression: An eye-tracking study. Journal of Abnormal Psychology, 122, 303. doi: 10.1037/a0031529 
Schofield, C. A., Johnson, A. L., Inhoff, A. W., \& Coles, M. E. (2012). Social anxiety and difficulty disengaging threat: Evidence from eye-tracking. Cognition and Emotion, 26, 300311. doi: 10.1016/j.nlm.2011.09.007

Sheehan, D. V., Lecrubier, Y., Sheehan, K. H., Amorim, P., Janvas, J., Weiller, E., ..., \& Dunbar, G. C. (1998). The Mini-International Neuropsychiatric Interview (MINI): the development and validation of a structured diagnostic psychiatric interview for DSM-IV and ICD-10. Journal of Clinical Psychiatry, 59, 22-33.

Stange, J. P., Alloy, L. B., \& Fresco, D. M. (2017). Inflexibility as a vulnerability to depression: A systematic qualitative review. Clinical Psychology: Science and Practice, 24, 245-276. doi: 10.1111/cpsp.12201

Troy, A. S. (2015). Reappraisal and resilience to stress: Context must be considered. Behavioral and Brain Sciences, 38. doi: 10.1017/S0140525X1400171X, e123

Troy, A. S., Shallcross, A. J., \& Mauss, I. B. (2013). A person-by-situation approach to emotion regulation: Cognitive reappraisal can either help or hurt, depending on the context. Psychological Science, 24, 2505-2514. doi: 10.1177/0956797613496434

Van Bockstaele, B., Verschuere, B., Tibboel, H., De Houwer, J., Crombez, G., \& Koster, E. H. W. (2014). A review of current evidence for the causal impact of attentional bias on fear and anxiety. Psychological Bulletin, 140, 682-721. doi: 10.1037/a0034834

Vogt, J., De Houwer, J., \& Moors, A. (2011). Unintended allocation of spatial attention to goal- relevant but not to goal-related events. Social Psychology, 42, 48-55. doi:10.1027/18649335/a000042 
Vogt, J., De Houwer, J., Moors, A., Van Damme, S., \& Crombez, G. (2010). The automatic orienting of attention to goal-relevant stimuli. Acta Psychologica, 134, 61-69. doi: 10.1016/j.actpsy.2009.12.006

Wagnild, G. M., \& Young, H. M. (1993). Development and psychometric evaluation of the Resilience Scale. Journal of Nursing Measurement, 1, 165-178.

Wardenaar, K. J., van Veen, T., Giltay, E. J., de Beurs, E., Penninx, B. W., \& Zitman, F. G. (2010). Development and validation of a 30-item short adaptation of the Mood and Anxiety Symptoms Questionnaire (MASQ). Psychiatry Research, 179, 101-106. doi: 10.1016/j.psychres.2009.03.005

Waugh, C. E., Thompson, R. J., \& Gotlib, I. H. (2011). Flexible emotional responsiveness in trait resilience. Emotion, 11, 1059-1067. doi: 10.1037/a0021786

Zvielli, A., Vrijsen, J. N., Koster, E. H. W., \& Bernstein, A. (2016). Attentional bias temporal dynamics in remitted depression. Journal of Abnormal Psychology, 125, 768-776. doi: $10.1037 / \mathrm{abn} 0000190$ 


\section{Figure Captions:}

Figure 1 Trial sequence in the task. All times are in milliseconds.

Figure 2 The time to make first fixations for both high and low dysphorics for each level of repeat goal and switch goal, when the context remained constant (i.e. context repeat condition). The first fixation times are provided for both 'look to positive' and 'look to negative' goals. First fixation times presented in milliseconds (along the y-axis). This figure provides within-group comparisons for the context repeat condition. Error bars represent standard error.

Figure 3 The time to make first fixations for both high and low dysphorics for each level of repeat goal and switch goal, when the context switched (i.e. context switch condition). The first fixation times are provided for both 'look to positive' and 'look to negative' goals. First fixation times presented in milliseconds (along the y-axis). This figure provides betweengroup comparisons for the context switch condition. Error bars represent standard error.

Figure 4 The time to make first fixations for both high and low dysphorics for each level of repeat goal and switch goal, when the context remained constant (i.e. context repeat condition) versus when the context switched (i.e. context switch condition). The first fixation times are provided for both 'look to positive' and 'look to negative' goals. First fixation times presented in milliseconds (along the y-axis). The figure provides within-group comparisons. Error bars represent standard error. 
Figure 1

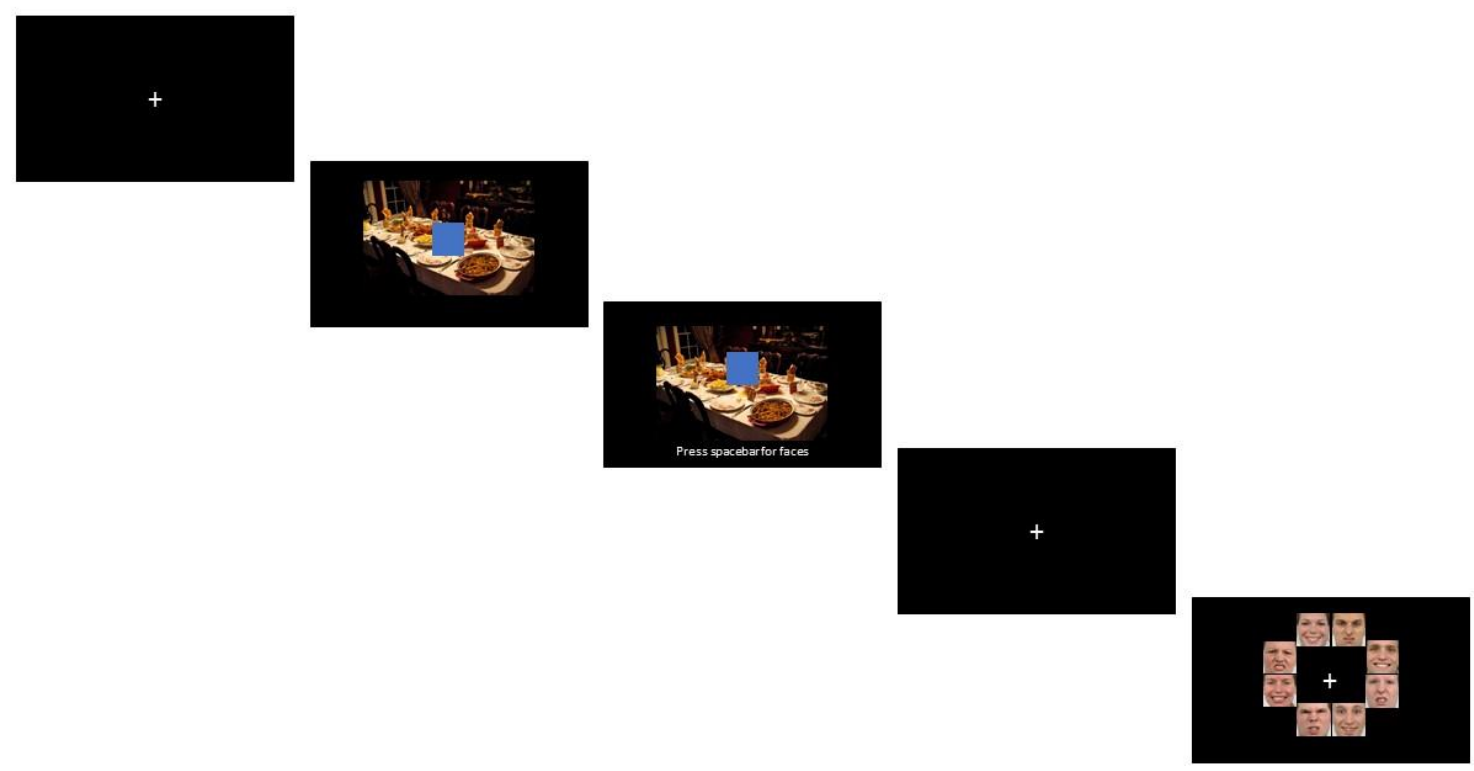


Figure 2

CONTEXT REPEAT CONDITION

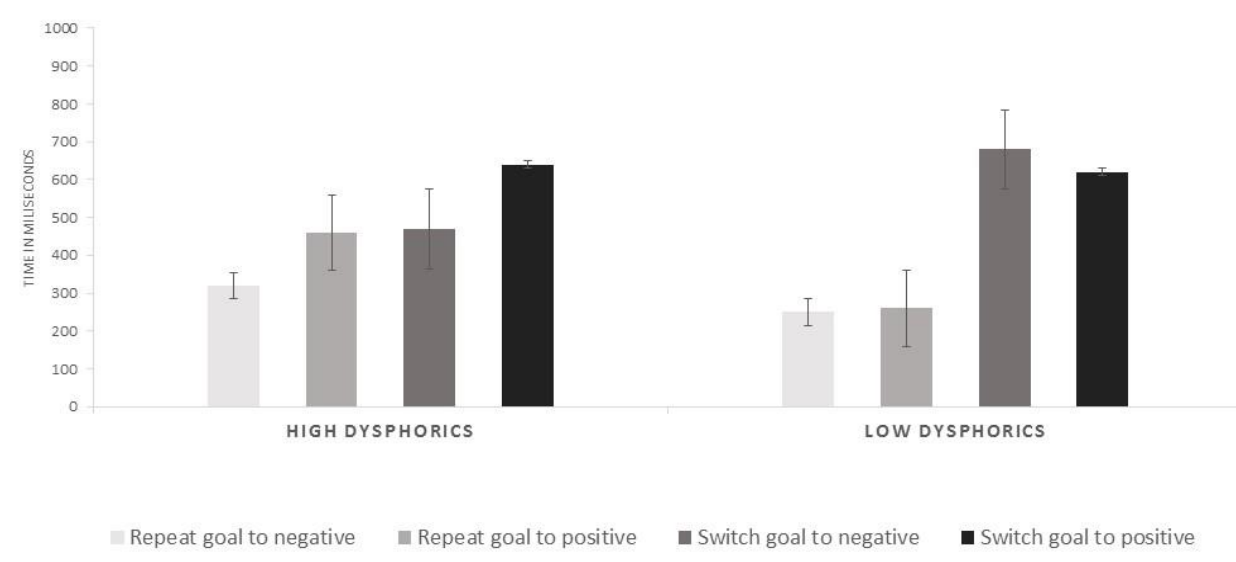




\section{CONTEXTUAL CHANGES INFLUENCE ATTENTION FLEXIBILITY}

Figure 3

CONTEXT REPEAT VS. CONTEXT SWITCH CONDITIONS

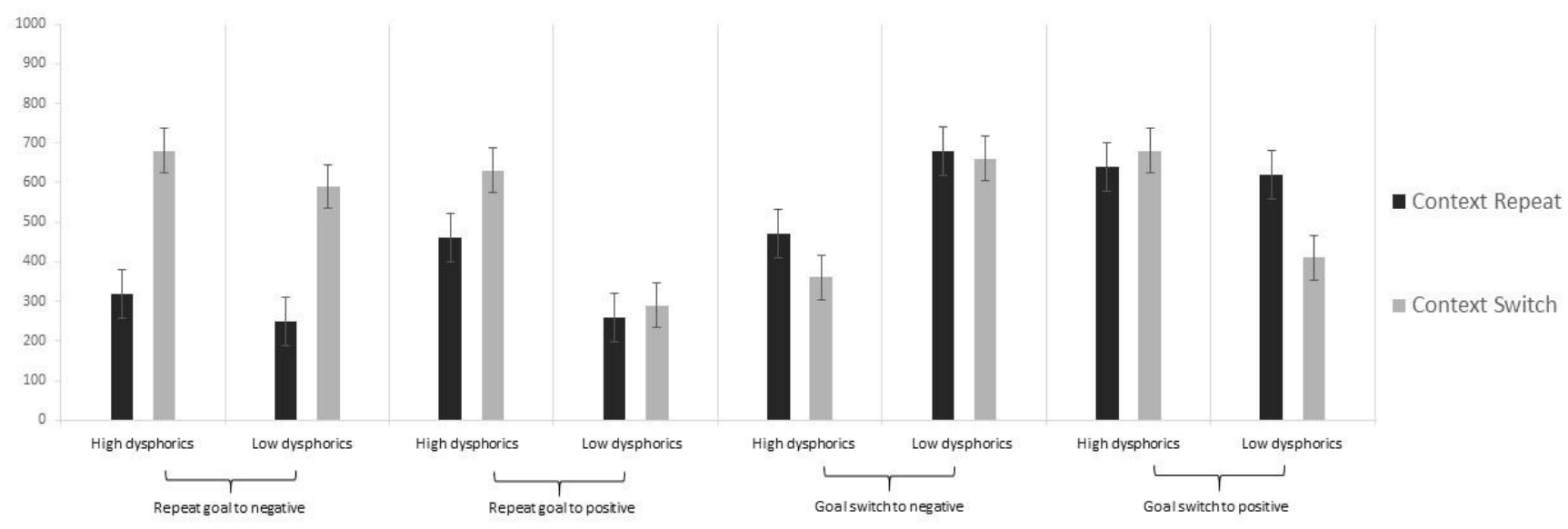




\section{Figure 4}

CONTEXT SWITCH CONDITION

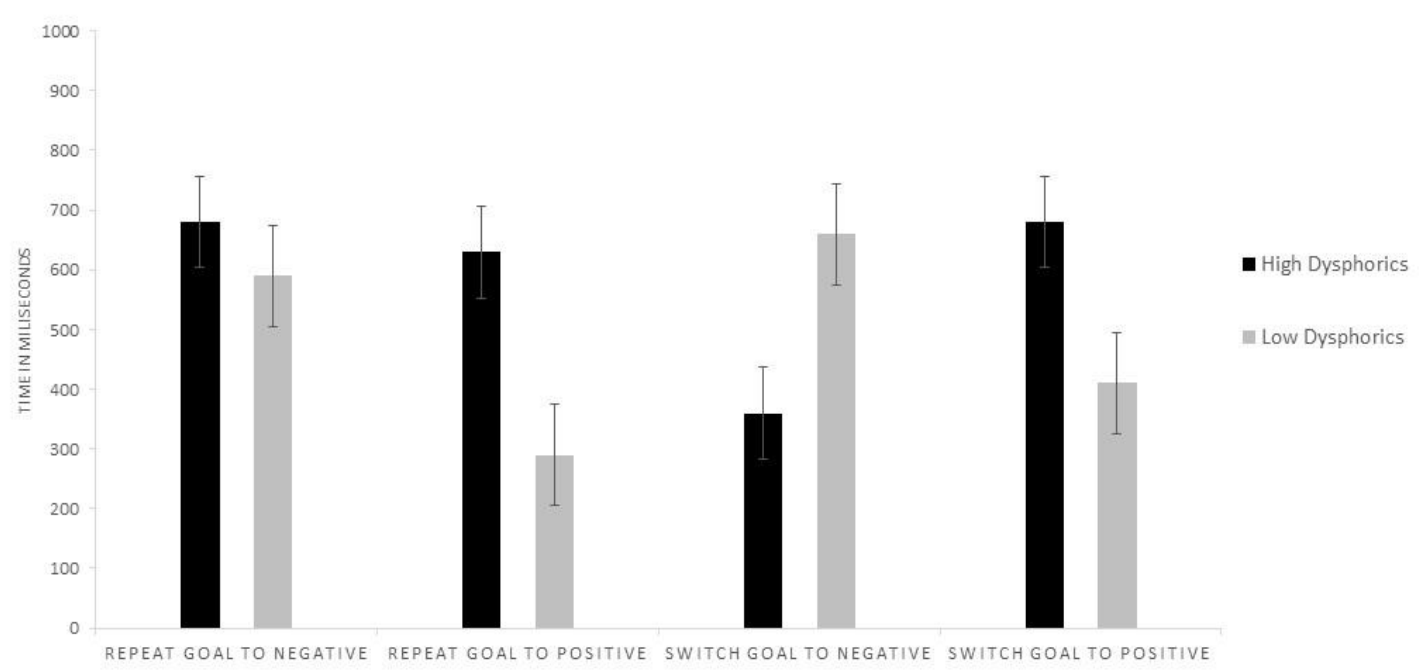




\section{Appendix I}

A description of the 4 social contexts developed for this study. Participants were presented with the text of each social context which briefly explained what took place in the context, along with the two goals that could be activated in each context. Along with the text, participants were presented with the 2 goal-activating objects, square and circle, which were associated with different goals in different contexts. Lastly, participants were also presented the context picture which represented the textual context in a pictorial form.

\begin{tabular}{c|c|}
\hline Context & Goal \\
\hline Dinner with colleagues: & To have an \\
$\begin{array}{c}\text { To have an enjoyable dinner, } \\
\text { it is best to pay attention to } \\
\text { people who look positive. }\end{array}$ & $\begin{array}{c}\text { Enjoyable } \\
\text { Dinner }\end{array}$ \\
$\begin{array}{c}\text { To avoid getting sick by } \\
\text { eating bad food, it is best to } \\
\text { pay attention to people who } \\
\text { look sick/negative. }\end{array}$ & $\begin{array}{c}\text { To avoid } \\
\text { Friend's party: }\end{array}$ \\
$\begin{array}{c}\text { To enjoy the party, it is best } \\
\text { to pay attention to people } \\
\text { who look positive. }\end{array}$ & $\begin{array}{c}\text { To enjoy the } \\
\text { Party }\end{array}$ \\
$\begin{array}{c}\text { After hearing a loud bang, to } \\
\text { protect self from harm, it is } \\
\text { best to pay attention to } \\
\text { people who look negative }\end{array}$ & $\begin{array}{c}\text { To protect } \\
\text { Self from } \\
\text { harm }\end{array}$ \\
\hline
\end{tabular}




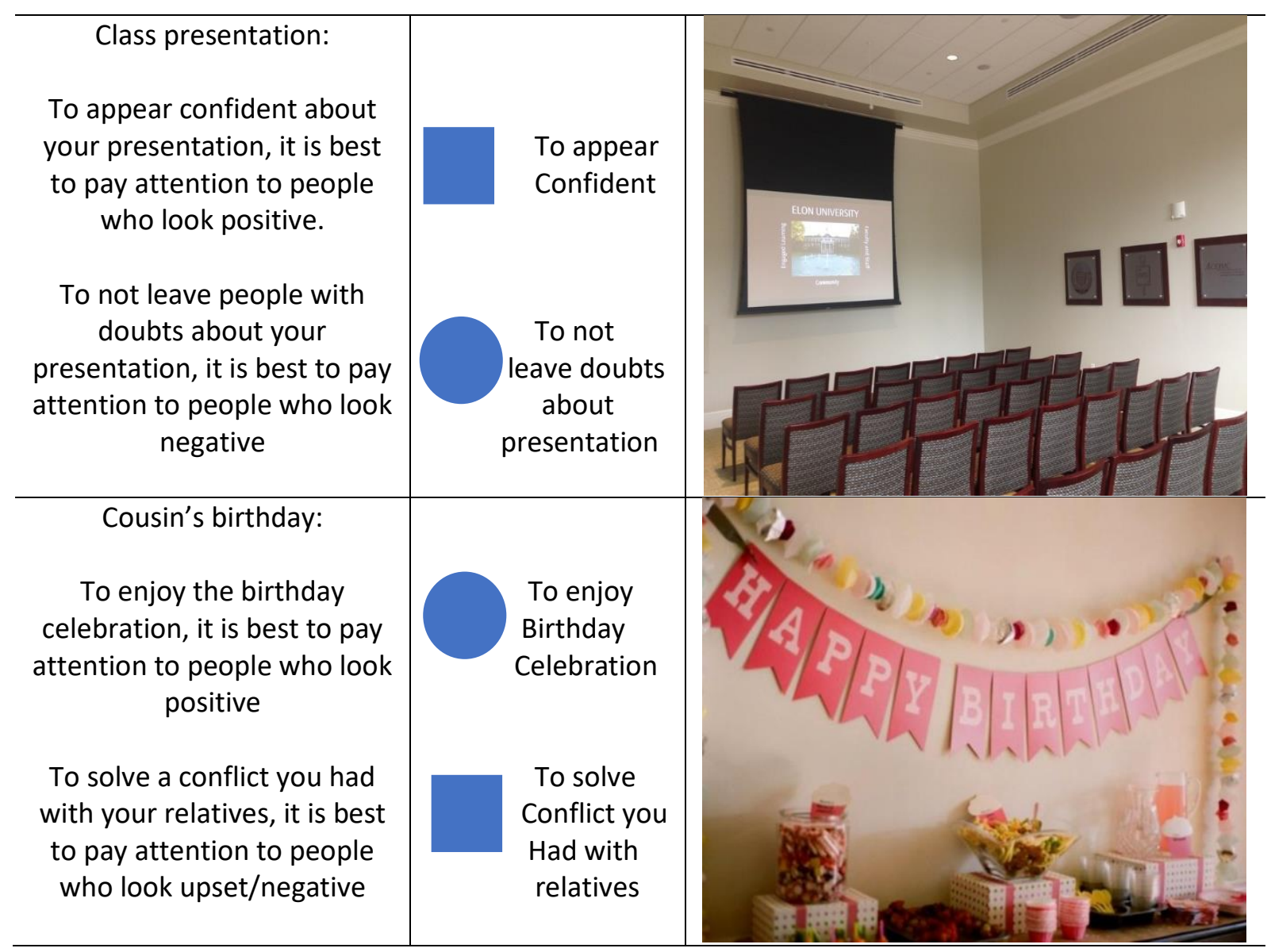




\section{Appendix II}

Here, we present the 4-way interaction decomposition below:

\begin{tabular}{|c|c|c|c|}
\hline Source & Test-value & p-value & Effect Size \\
\hline $\begin{array}{l}2 \text { (Context Switch) x } 2 \text { (Goal Switch) x } 2 \text { (Goal Type) } \\
\text { x } 2 \text { (Group) }\end{array}$ & $F(1,49)=4.59$ & $p<.05^{*}$ & $\eta_{p}{ }^{2}=.09$ \\
\hline $\begin{array}{l}2 \text { (Context Switch) x } 2 \text { (Goal Switch) x } 2 \text { (Group) } \\
\text { (Goal Type level: Look to positive) }\end{array}$ & $F(1,49)=2.04$ & $p=.16$ & $\eta_{p}^{2}=.04$ \\
\hline $\begin{array}{l}2 \text { (Context Switch) x } 2 \text { (Goal Switch) x } 2 \text { (Group) } \\
\text { (Goal Type level: Look to negative) }\end{array}$ & $F(1,49)=.65$ & $p=.42$ & $\eta_{p}^{2}=.01$ \\
\hline $\begin{array}{l}2 \text { (Context Switch) x } 2 \text { (Goal Type) x } 2 \text { (Group) } \\
\text { (Goal Switch level: Repeat goal) }\end{array}$ & $F(1,49)=2.46$ & $p=.12$ & $\eta_{p}^{2}=.05$ \\
\hline $\begin{array}{l}2 \text { (Context Switch) x } 2 \text { (Goal Type) x } 2 \text { (Group) } \\
\text { (Goal Switch level: Switch goal) }\end{array}$ & $F(1,49)=19.24$ & $p<.001 * *$ & $\eta_{p}^{2}=.28$ \\
\hline $\begin{array}{l}2 \text { (Context Switch) x } 2 \text { (Group) } \\
\text { (Goal Type level: Look to positive) }\end{array}$ & $F(1,49)=18.36$ & $p<.001 * *$ & $\eta_{p}^{2}=.27$ \\
\hline $\begin{array}{l}2 \text { (Context Switch) x } 2 \text { (Group) } \\
\text { (Goal Type level: Look to negative) }\end{array}$ & $F(1,49)=2.84$ & $p=.056$ & $\eta_{p}{ }^{2}=.07$ \\
\hline $\begin{array}{l}\text { T-test for variable Context Switch (Level: Switch } \\
\text { context) }\end{array}$ & $t(49)=.5 .29$ & $p<.001 * *$ & $d=1.47$ \\
\hline $\begin{array}{l}\text { T-test for variable Context Switch (Level: Repeat } \\
\qquad \text { context) }\end{array}$ & $t(49)=.32$ & $p=.752$ & $d=.09$ \\
\hline
\end{tabular}


Here, we present the 3-way interaction decomposition for the high dysphoric group:

\begin{tabular}{cccc}
\hline Source & Test-value & p-value & Effect Size \\
\hline 2 (Context Switch) x 2 (Goal Switch) x 2 (Goal Type) & $F(1,23)=14.42$ & $p=.001 * *$ & $\eta_{p}{ }^{2}=.39$ \\
\hline 2 (Context Switch) x 2 (Goal Switch) & $F(1,23)=7.20$ & $p=.013^{*}$ & $\eta_{p}{ }^{2}=.24$ \\
(Goal Type level: Look to positive) & & & \\
\hline 2 (Context Switch) x 2 (Goal Switch) & $F(1,23)=40.60$ & $p<.001 * *$ & $\eta_{p}{ }^{2}=.64$ \\
(Goal Type level: Look to negative) & & & \\
\hline 2 (Context Switch) x 2 (Goal Type) & $F(1,23)=11.97$ & $p=.002^{*}$ & $\eta_{p}{ }^{2}=.34$ \\
(Goal Switch level: Repeat goal) & & \\
\hline 2 (Context Switch) x 2 (Goal Type) & $F(1,23)=4.54$ & $p<.04 *$ & $\eta_{p}{ }^{2}=.17$ \\
(Goal Switch level: Switch goal) & & \\
\hline
\end{tabular}

Here, we present the 3-way interaction decomposition for the low dysphoric group:

\section{$\begin{array}{llll}\text { Source } & \text { Test-value } & \text { p-value } & \text { Effect Size }\end{array}$}

2 (Context Switch) x 2 (Goal Switch) x 2 (Goal Type) $\quad F(1,26)=9.49 \quad p=.005^{*} \quad \eta_{p}^{2}=.27$

2 (Context Switch) x 2 (Goal Switch) $\quad F(1,26)=24.88 \quad p<.001^{* *} \quad \eta_{p}{ }^{2}=.49$

(Goal Type level: Look to positive)

2 (Context Switch) x 2 (Goal Switch) $\quad F(1,26)=52.90 \quad p<.001^{* *} \quad \eta_{p}^{2}=.67$

(Goal Type level: Look to negative)

$2\left(\right.$ Context Switch) x 2 (Goal Type) $\quad F(1,26)=140.65 \quad p=.002 * \quad \eta_{p}{ }^{2}=.84$

(Goal Switch level: Repeat goal)

$2\left(\right.$ Context Switch) x 2 (Goal Type) $\quad F(1,26)=21.29 \quad p<.001^{* *} \quad \eta_{p}^{2}=.45$

(Goal Switch level: Switch goal) 


\section{Bayesian analyses}

We conducted analyses using JASP (version 0.9.2.0; 2019). We used BF10, which is the probability of the alternative hypothesis relative to the null hypothesis, and we employed default priors (Cauchy scale: .0707) in our analyses. We interpreted the Bayes factors as follows: $\mathrm{BF} 10<.01=$ Decisive evidence for $\mathrm{H} 0 ; \mathrm{BF} 10=.01-.033=$ Very strong evidence for $\mathrm{H} 0 ; \mathrm{BF} 10=.033-.1=$ Strong evidence for $\mathrm{H} 0 ; \mathrm{BF} 10=.1-.33=$ Substantial evidence for $\mathrm{H} 0 ; \mathrm{BF} 10=.3-1=$ Anecdotal evidence for $\mathrm{H} 0 ; \mathrm{BF} 10=1=$ no evidence for either hypothesis; $\mathrm{BF} 10=1-3=$ Anecdotal evidence for $\mathrm{H} 1 ; \mathrm{BF} 10=3-10=$ Substantial evidence for $\mathrm{H} 1 ; \mathrm{BF} 10=10-30=$ Strong evidence for $\mathrm{H} 1 ; \mathrm{BF} 10=30-100=$ Very strong evidence for $\mathrm{H} 1 ; \mathrm{BF} 10>100=$ Decisive evidence for $\mathrm{H} 1$.

\section{First hypothesis}

When the context was constant (i.e., repeated from the previous trial), using Bayesian paired t-test comparison we found strong evidence $(\mathrm{BF}=53.81)$ suggesting that high dysphoric individuals had faster first fixations when switching from a positive to a negative goal in comparison to switching from a negative to a positive goal. Similarly, when the context remained constant, we found substantial evidence $(\mathrm{BF}=7.30)$ indicating that high dysphoric individuals had faster first fixations when repeating attention to a negative goal in comparison to a positive goal. These findings are consistent with the frequentist analysis.

\section{Second hypothesis}

Using Bayesian paired t-test comparison, we found substantial evidence for the null $(\mathrm{BF}=$ .24) indicating that for low dysphorics there were no significant differences in first fixations when repeating attention to negative or positive goals, when the context was constant. This finding is consistent with the frequentist analysis. However, we found anecdotal evidence in favor of the null $(\mathrm{BF}=.49)$ indicating that we could not claim with certainty that there were 
no significant differences for low dysphorics in switching attention to positive or negative goals when the context was constant. This finding deviates from the result from the frequentist analysis, wherein we found a statistically significant result for no differences in switching towards positive or negative goals when context is repeating. This discrepancy suggests that we cannot ultimately conclude with certainty, and replication of the study is needed in order to clarify this finding.

\section{Third hypothesis}

Repeating goals. In line with our third hypothesis that contextual changes would create difficulties for all individuals, using Bayesian paired t-test comparisons we found very strong to decisive evidence indicating that high dysphorics were slower when repeating attention to positive $(\mathrm{BF}=50.70)$ and negative $(\mathrm{BF}>100)$ goals. Further, we found decisive evidence $(\mathrm{BF}$

$>100$ ) indicating that low dysphoric individuals were slower when repeating attention to negative goals. These findings are consistent with the frequentist analysis. However, for the comparison between context repeat vs. context switch when repeating attention to positive we found anecdotal evidence $(\mathrm{BF}=2.81)$ for low dysphorics. This suggests that we cannot claim that low dysphorics were significantly slower in repeating attention to positive goals when the context switched versus repeating. This finding deviates somewhat from the frequentist analysis, wherein we found that low dysphorics were significantly slower to repeat attention to positive goals when context switched vs. when context repeated. Once again, this discrepancy suggests that we cannot ultimately conclude with certainty, and replication of the study is needed in order to clarify this finding.

Switching goals. Bayesian paired t-test comparisons provided substantial evidence $(\mathrm{BF}=$ 3.04) indicating that high dysphoric individuals had faster fixations when switching attention from a positive to a negative goal when the context was switching as compared to when the context was repeating. However, when switching from negative to positive goals, we found 
substantial evidence for the null $(\mathrm{BF}=.15)$, indicating that there were no significant differences for high dysphorics in fixation latencies when the context was switching vs. when the context was repeating. In contrast, we found decisive evidence $(\mathrm{BF}>100)$ indicating that low dysphoric individuals had faster first fixations when switching attention from a negative to a positive goal when the context was switching as compared to when the context was repeating. However, when switching from a positive to a negative goal, we found substantial evidence for the null $(\mathrm{BF}=.28)$, suggesting a consistent lack of differences in fixation times when the context was switching vs. repeating. These results are in line with our findings from the frequentist analysis, as reported in the manuscript.

\section{Fourth hypothesis}

For conditions where the context switched (i.e., changed from the previous trial), pairwise comparisons found decisive evidence indicating that high, compared to low dysphorics, found it more difficult to both repeat attention $(\mathrm{BF}>100)$ and switch attention $(\mathrm{BF}>100)$ towards positive goals. Meanwhile, we only found anecdotal evidence $(\mathrm{BF}=2.67)$ indicating that high dysphorics had more difficulties compared to low dysphorics in repeating attention to negative goals when context was switching. Finally, we found substantial evidence for the null $(\mathrm{BF}=.01)$ when switching towards negative goals. This indicates that high dysphorics, compared to low dysphorics, were faster in switching attention from positive towards negative goals when the context was switching. Again, these results are consistent with findings from the frequentist analysis. 


\section{Appendix III}

This table provides the correlation between the scores on the Anhedonic Depression subscale of Mood and Anxiety Symptoms Questionnaire - D30 (MASQ - D30) and the 8 attention switching indices. In the second column correlations are provided for attention switching indices and the overall scores on MASQ - D 30. ${ }^{* *}$ Correlation is significant at the 0.01 level (2-tailed). *Correlation is significant at the 0.05 level (2-tailed).

\begin{tabular}{|c|c|c|}
\hline Attention switching index & $\begin{array}{c}\text { Anhedonic Depression subscale (p- } \\
\text { value) }\end{array}$ & $\begin{array}{c}\text { Total MASQ - D30 (p- } \\
\text { value })\end{array}$ \\
\hline $\begin{array}{c}\text { Context repeat - Goal repeat } \\
\text { (Look to negative) }\end{array}$ & $.14(p=.32)$ & $.07(p=.62)$ \\
\hline $\begin{array}{c}\text { Context repeat - Goal repeat } \\
\text { (Look to positive) }\end{array}$ & $.31 *(p=.029)$ & $.27(p=.056)$ \\
\hline $\begin{array}{l}\text { Context repeat - Goal switch } \\
\text { (Look to negative) }\end{array}$ & $-.54 * *(p<.001)$ & $-.38 * *(p=.006)$ \\
\hline $\begin{array}{c}\text { Context repeat - Goal switch } \\
\text { (Look to positive) }\end{array}$ & $.17(p=.25)$ & $.23(p=.11)$ \\
\hline $\begin{array}{l}\text { Context switch - Goal repeat } \\
\text { (Look to negative) }\end{array}$ & $.19(p=.17)$ & $.18(p=.19)$ \\
\hline $\begin{array}{c}\text { Context switch - Goal repeat } \\
\text { (Look to positive) }\end{array}$ & $.68^{* *}(p<.001)$ & $.55 * *(p<.001)$ \\
\hline $\begin{array}{l}\text { Context switch - Goal switch } \\
\text { (Look to negative) }\end{array}$ & $-.60 * *(p<.001)$ & $-.48 * *(p<.001)$ \\
\hline $\begin{array}{l}\text { Context switch - Goal switch } \\
\text { (Look to positive) }\end{array}$ & $.35^{*}(p=.012)$ & $.29 *(p=.035)$ \\
\hline
\end{tabular}




\section{Appendix IV}

During the attention flexibility task, participants were introduced to the 4 contexts, their associated goals, and the corresponding context picture and the goal objects. Participants memorized this information, which was then presented in the form of a reaction-time task using eye-tracking. Each trial for the task began with a fixation cross for 500ms. This was replaced by a picture of a context with a goal object on top of it. After fixation on the goal object for $100 \mathrm{~ms}$, participants saw the sentence "Press spacebar for faces". At this point participants could take as long as they needed to recall the correct response (attend to positive or attend to negative), based upon the context picture and the goal object combination presented on the screen. Once the participants were ready, they pressed the spacebar and saw a fixation cross for $500 \mathrm{~ms}$, followed by 8 emotional faces around the cross.

Data Preparation. In order to assess how quickly participants were able to mentalshift between different contextual goals, we measured the time it took participants to press the spacebar. We obtained the total presentation time of context and goal cue for each trial, measured from the moment the context picture appeared on the screen with the goal object on top of it until the moment participants pressed the spacebar to view the faces. Total cue presentation times were obtained for each of the 128 trials. From the total cue presentation times we were able to calculate the set-shifting variables. We calculated 8 set-shifting variables: Repeat Context - Repeat Goal (Look to positive), Repeat Context - Repeat Goal (Look to negative), Repeat Context - Switch Goal (Look to positive), Repeat Context - Switch Goal (Look to negative), Switch Context - Repeat Goal (Look to positive), Switch Context Repeat Goal (Look to negative), Switch Context - Switch Goal (Look to positive), and Switch Context - Switch Goal (Look to negative). This index allowed us to ascertain how quickly participants were able to mentally set-shift between the different contextual goals, separately from the attention switching indices. 
Results. A 2 (Context Switch) x 2 (Goal Switch) x 2 (Goal) x 2 (Group) mixed analysis of variance (ANOVA) was conducted with the 'Total cue presentation time' variable as dependent variable. Group (High vs. Low dysphorics) was the between-subjects factor. Context Switch (Repeat vs. Switch Context), Goal Switch (Repeat vs. Switch Goal), and Goal (Look to positive vs. look to negative) were the within-subjects factors. We found significant main effects for Context Switch, $F(1,49)=100.89, p<.001, \eta_{p}^{2}=.67$, Goal Switch, $F(1,49)$ $=43.95, p<.001, \eta_{p}{ }^{2}=.47$, and Goal, $F(1,49)=34.75, p<.001, \eta_{p}{ }^{2}=.42$. These main effects were qualified by a significant three-way Context Switch x Goal Switch x Group interaction, $F(1,49)=6.62, p=.013, \eta_{p}^{2}=.12$.

In order to decompose the significant 3-way interaction above, we conducted four separate 2 (Context Switch) x 2 (Group) mixed ANOVAs for each level of Goal Switch. We found 4 significant interactions. First, we found significant Context Switch x Group interactions for the 'Goal Repeat' level when the goal was positive, $F(1,49)=23.12, p<$ $.001, \eta_{p}{ }^{2}=.32$, and when the goal was negative, $F(1,49)=40.14, \mathrm{p}<.001, \eta_{p}{ }^{2}=.45$. Next, we found significant Context Switch x Group interactions for the 'Goal Switch' level when the goal was positive, $F(1,49)=33.82, p<.001, \eta_{p}^{2}=.41$, and when the goal was negative, $F(1,49)=56.79, p<.001, \eta_{p}^{2}=.54$.

Significant Bonferroni-corrected pairwise comparisons revealed that high dysphorics had longer presentation times (i.e. they took longer to press the spacebar) when the context switched, compared to when the context was repeating, both while repeating positive goals ( $p$ $<.001)$ and while switching towards positive goals $(p<.001)$. Meanwhile within-group comparisons showed that low dysphorics did not have significantly longer presentation times (i.e. they were faster in pressing the spacebar) when context switched, compared to when the context was repeating, both while repeating positive goals $(p=.121)$ and while switching 
towards positive goals $(p=.128)$. Further, significant within-group comparisons revealed that high dysphorics also had longer presentation times when the context switched, as opposed to when it repeated, both while repeating negative goals $(p<.001)$ and when switching towards negative goals $(p<.001)$. Low dysphorics, on the other hand, had significantly longer presentation times when the context switched, compared to when the context repeated, when repeating negative goals $(p=.039)$. However, low dysphorics did not have significantly longer presentation times when the context switched, while switching attention towards negative goals $(p=.230)$. Lastly, significant pairwise comparison revealed that high compared to low dysphoric individuals had longer presentation times when the context switched, both while repeating and switching to both positive and negative goals (all $p$ s < .001 ; see Figure 1 below).

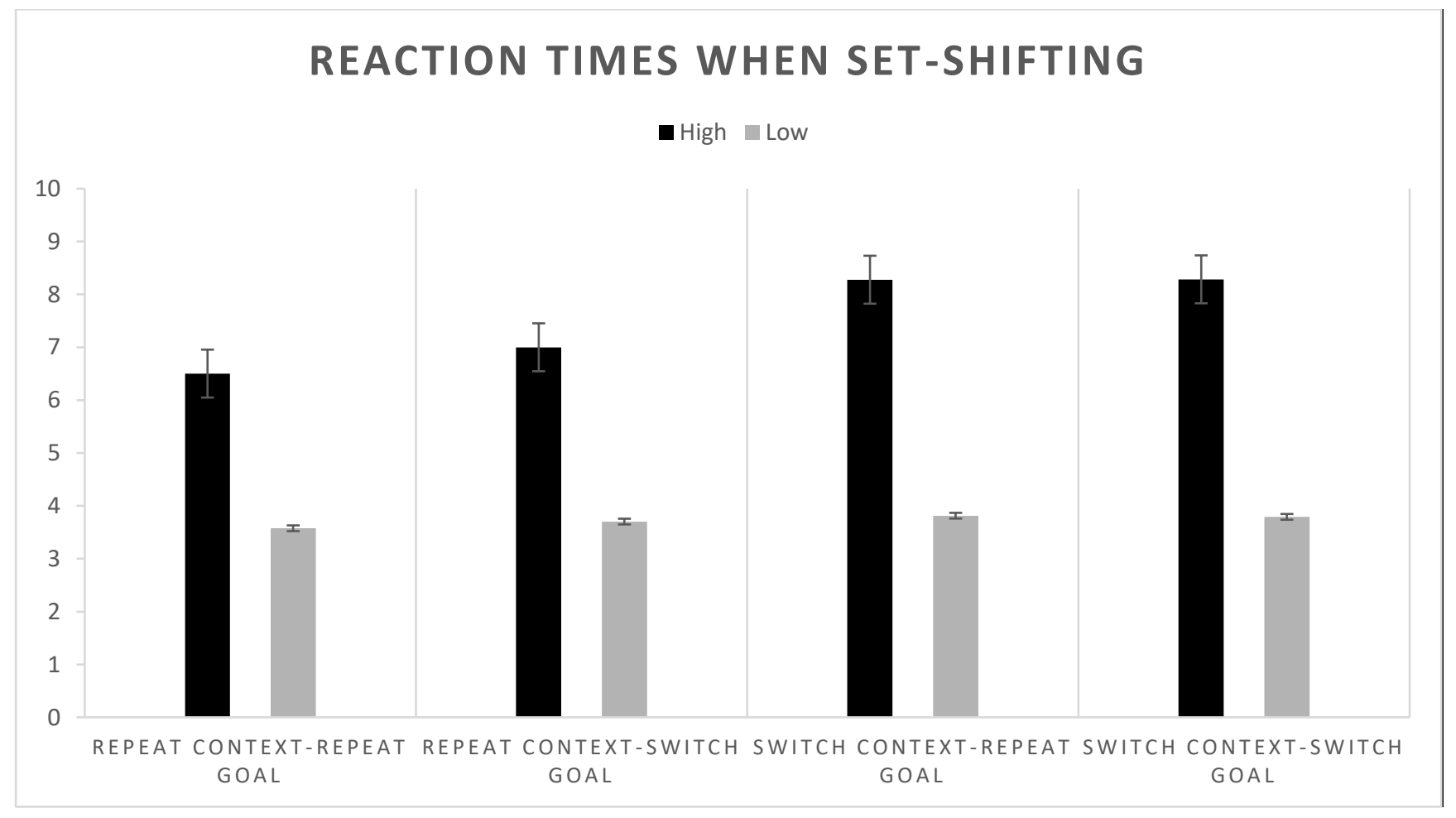

Figure 1 Reaction times (i.e., time to press spacebar) are presented for both high and low dysphorics for the four different conditions, combinations of Context Switch (Repeat vs. 
switch context) and Goal Switch (Repeat vs. switch goal). Times are presented in seconds (along the $\mathrm{y}$-axis). High $=$ high Dysphoric, Low = low Dysphoric. 